\title{
SÍNTESE SOBRE O COMPORTAMENTO ORGANIZACIONAL E A IMPORTÂNCIA DA GESTÃO DE PESSOAS BASEADOS NO HISTÓRICO DA ADMINISTRAÇÃO
}

\section{ARTIGO ORIGINAL}

MENDONÇA, Lorenna Lima ${ }^{1}$

MENDONÇA, Lorenna Lima. Síntese sobre o comportamento organizacional e a importância da gestão de pessoas baseados no histórico da administração. Revista Científica Multidisciplinar Núcleo do Conhecimento. Ano 05, Ed. 11, Vol. 11, pp. 21-35. Novembro de 2020. ISSN: 2448-0959, Link de acesso:https://www.nucleodoconhecimento.com.br/administracao/sintese

\section{RESUMO}

O presente trabalho traz um breve histórico a respeito da Administração bem como sobre a Organização, trazendo referências de alguns autores como Chiavenato, Gil e Ribeiro, onde estes mencionam a importância de a Organização ter um setor de Gestão Pessoal para o melhor desenvolvimento da empresa. É feito ainda uma breve explicação sobre o que é a Gestão de Pessoas, onde esta é de primordial importância para qualquer empresa, não sendo só "mais um" setor da Empresa, e que a mesma se baseia em três aspectos fundamentais, onde a primeira é tratar as pessoas como seres humanos; a segunda, as pessoas são como meros recursos (humanos) organizacionais; e o terceiro fundamento é que as pessoas são como parceiras da organização. A Gestão de Pessoas irá trabalhar os aspectos morais e sociais do colaborador e a sua função gerencial, que visa à cooperação das pessoas que atuam nas organizações para o alcance dos objetivos tanto organizacionais quanto individuais. Este trabalho traz ainda, um breve histórico e uma análise sobre o Comportamento Organizacional, onde este pode ser considerado um Campo de

\footnotetext{
${ }_{1}^{1}$ MBA Em Marketing E Recursos Humanos. Pós graduação em Gestão em Serviço Social e Políticas públicas. Graduação em Serviço Social.
} 
Estudos e que o mesmo se volta a prever, explicar, entender e modificar o comportamento do ser humano dentro das organizações. Será explanado ainda de forma simples, as três áreas do Comportamento Organizacional, que são: Comportamento Micro Organizacional; Comportamento Meso Organizacional e Comportamento Macro Organizacional. Para o desenvolvimento deste artigo, foi utilizado o método da pesquisa bibliográfica onde a mesma busca conhecer e analisar as contribuições culturais ou científicas do passado existentes sobre um determinado assunto, tema ou problema. Tal artigo teve embasamento teórico em alguns livros como: Introdução à teoria geral da administração; Novos desafios da gestão de pessoas; Administração de recursos humanos; Gestão de pessoas e Comportamento organizacional. E para concluir o presente trabalho, foi explanado sobre a importância e valor do Comportamento Organizacional na vida dos colaboradores e nas organizações.

Palavras Chaves: Administração, Gestão de Pessoas, Comportamento Organizacional.

\section{INTRODUÇÃO}

O enfoque deste trabalho se baseia no histórico da Administração, bem como nos aspectos relevantes do Comportamento Organizacional, onde este é de suma importância para as empresas. Sendo que, o mesmo é um campo de estudos que investiga o impacto que os indivíduos, os grupos e a estrutura têm sobre as organizações, e o propósito desta, é utilizar este conhecimento para melhorar a qualidade organizacional.

O comportamento organizacional irá aplicar o conhecimento adquirido sobre os grupos e as pessoas, ou mais especificamente, sobre os colaboradores, fazendo com que as organizações adquiram mais qualidade em seu trabalho. Sendo que as organizações não se comandam sozinhas, e daí a necessidade do estudo e aplicação do comportamento organizacional dentro das empresas e sobre os colaboradores. 
Compreender o comportamento organizacional torna-se importante pelo fato de que este irá trabalhar na dinâmica de manutenção e melhoria dos avanços da gestão de pessoas, pois irá determinar o que os líderes devem fazer, e quais as chances de presumir o que pode ou não acontecer, e em particular evitar certos problemas individuais e/ou coletivos entre os colaboradores, bem como elaborar alguns métodos de liderança e estratégias de gestão que existem para o alcance de metas e resultados que se deseja.

Estudar o comportamento organizacional faz-se mister no momento em que este visa também levar um melhor entendimento sobre os espaços organizacionais acerca do comportamental e cultural para o desenvolvimento contínuo das organizações. Onde este trabalho irá proporcionar um melhor entendimento sobre o mesmo.

Diante do exposto, a pesquisa bibliográfica que fora aplicada neste artigo, teve por objetivo trazer um melhor entendimento sobre o comportamento organizacional, trazendo o seu significado e a importância do mesmo dentro das organizações.

\section{REFERENCIAL TEÓRICO}

\subsection{BREVE HISTÓRICO DA ADMINISTRAÇÃO}

No decorrer dos anos, os homens sempre buscaram meios para aplicarem os seus esforços e fazer com que alcançassem melhores resultados nos seus projetos, onde estes aprenderam a reunir forças e a trabalhar em equipe, fazendo assim com estes conseguissem inventar a organização. Segundo Chiavenato $(2014$, p. 1) foi "o motor do desenvolvimento econômico e social que permitiu chegarmos ao mundo moderno, o carro - chefe da inovação e da transformação da sociedade contemporânea".

Mediante as criações do homem, aquela que cresce e se destaca por ser a mais incompreensível e maravilhosa é evidentemente a organização, ou seja, a forma lógica de se trabalhar, iniciar, arquitetar, produzir e distribuir bens e serviços. Porém, não há como existir duas organizações iguais, sendo perceptível que cada uma terá sua própria personalidade, sua natureza especial, terá também suas características 
singulares, seu desempenho e seus resultados. Claramente as organizações se apresentam com grandes diversidades e são diferentes entre si. (CHIAVENATO, 2014).

Conforme Chiavenato (2014), a Organização fez-se muito importante ao longo da história, sem contar que a mesma, age em diferentes ambientes sendo contornada por vários fatores como os econômicos, políticos, tecnológicos, legais, sociais, culturais e demográficos, interagindo entre si e alternando-se constantemente, sendo proporcionado um campo dinâmico de forças que se caracteriza por uma enorme mudança e instabilidade ao redor.

Dentro da organização, faz-se necessário ter uma equipe competente que possa realizar uma Administração apropriada, fazendo com que a liderança desta organização haja e decida prudentemente nas diversas situações que lhes surgir, e como consequência da boa organização e administração, haverá resultados elevados de maneira eficiente e eficaz. Conforme Chiavenato (2014) é a Administração que faz as coisas acontecerem, sendo que a mesma envolve simultaneamente a arte, a técnica e a ciência. A Administração é resultado.

De acordo com Chiavenato (2014) a organização é o método ao qual a sociedade atinge os seus objetivos. E para que as organizações consigam alcançar suas metas, é para isso que a Administração é usada como ferramenta, função ou instrumento para produzir o desenvolvimento. Diante disso, a Administração não acontece isoladamente, e sim dentro das organizações.

Dentro dessa Administração, há a Teoria das Relações Humanas, que traz à tona o cuidado que o chefe deve ter com os funcionários dentro de uma empresa. Ressaltando que os funcionários sejam reconhecidos e bem cuidados pelo trabalho que realizam.

Os principais legados da Teoria das Relações Humanas à TGA, almejam humanizar as empresas, trazendo uma ênfase na organização informar, bem como nos grupos sociais, nas comunicações, no incentivo, na direção, nas abordagens participativas, e 
não menos importante, o interesse em saber como está a satisfação no trabalho. (CHIAVENATO, 2014).

"Diante da necessidade de corrigir a tendência à desumanização do trabalho com a aplicação de métodos científicos precisos, foi que nasceu a Teoria das Relações Humanas". (CHIAVENATO, 2014, p. 30). Conforme o autor, esta teoria foi criada com o objetivo de que os trabalhadores fossem valorizados e gratificados pelo trabalho que exercem na empresa.

Segundo Chiavenato, (2014, p.108), a Teoria das Relações Humanas tem suas origens em alguns fatores, como na primordialidade de civilizar e socializar a Administração; dentro do crescimento das ciências humanas, sobretudo a psicologia, têm-se também o seu desenvolvimento intelectual, sua aplicabilidade em organizações industriais, sendo assim, é perceptível que as ciências humanas expuseram o desacordo dos primórdios da Teoria Clássica; têm-se também as ideologias do filósofo Jhon Deway, e da psicologia dinâmica de Kurt Lewin para o crescimento do humanismo na Administração; uma experiência denominada de Hawthorne, que fora realizada em 1929 e 1932, trouxe um contratempo para os princípios da Teoria Clássica da Administração.

Após uma breve explicação sobre a organização, a administração e o surgimento das Relações Humanas, cabe explanar um pouco sobre os Recursos Humanos (Gestão de Pessoas), que se faz importante em todos os lugares, principalmente dentro da Administração.

\subsection{A IMPORTÂNCIA DA GESTÃO DE PESSOAS}

Segundo Chiavenato (2011), o mundo tem se transformado rapidamente, até mesmo na área de Recursos Humanos, onde são nomeados da seguinte forma: Gestão de Pessoas, Gestão com Pessoas, Administração do Capital Intelectual, Gestão de Talento Humano, Gestão de Competência, entre outros para manterem configurados na área e representados em um novo espaço. 
Entende-se que a Gestão de Pessoas é de primordial importância para qualquer empresa, não sendo esta só mais um setor da Empresa. "A Gestão de Pessoas ou ARH (Administração de Recursos Humanos) é o conjunto de decisões integradas sobre as relações de emprego que influenciam a eficácia dos funcionários e das organizações (CHIAVENATO,1999, p.35). O mesmo autor ainda diz que, "a Gestão de Pessoas se baseia em três aspectos fundamentais: 1. As pessoas como seres humanos; 2. As pessoas são como meros recursos (humanos) organizacionais; 3. As pessoas como parceiras da organização" (CHIAVENATO, 2002, p. 20).

Conforme o autor entende-se que a Gestão de Pessoas irá trabalhar os aspectos morais e sociais do trabalhador, que por sua vez, passa a ser chamado de Colaborador, pois este de certa forma começa a não somente trabalhar para o Empresário, mas passa a contribuir com a Empresa onde estão fornecendo os seus serviços.

Segundo o autor Gil (2001, p. 17) "a Gestão de Pessoas é a função gerencial que visa à cooperação das pessoas que atuam nas organizações para o alcance dos objetivos tanto organizacionais quanto individuais".

Mediante isso, Dessler, (2003, p. 2) expõe que a Administração se atribui à experiências e políticas necessárias em relação a guiar pessoas no trabalho de gerenciamento, particularmente em relação à contratação, ensino, análise, honorário, não podendo esquecer também um lugar seguro para os colaboradores da empresa. Vale ressaltar que entre as experiências e políticas, tem-se também que orientar qual a função de cada colaborador; verificar qual a imprescindibilidade de solicitar, selecionar, orientar e treinar novos candidatos, bem como outras atividades relacionadas a entrevistas, avaliação e condução de novos funcionários. Relacionado ao gerente, faz-se necessário que este saiba sobre chances iguais e ações afirmativas, bem como o bem-estar do funcionário e suas queixas e relações trabalhistas.

Antes, o Recursos Humanos tinha um papel mais controlador, rígido e misterioso. De acordo com Ribeiro (2005, p. 16), eram as seguintes: 
Controlar rigidamente a carreira dos funcionários; - Manter as escalas salariais em segredo, de tal forma que nem os gerentes saibam como tal escala funciona; - Manter a avaliação de potencial como uma tarefa exclusiva da função de Recursos Humanos; - Entender que a manutenção de um clima organizacional adequado é tarefa exclusiva de Recursos Humanos; - Manter tudo o que diga respeito a Recursos Humanos em um clima cheio de mistérios e segredos; - Conservar a imagem de Recursos Humanos com um departamento fechado e à parte da organização; - Valorizar excessivamente a área, em detrimento dos objetivos estratégicos da empresa; - Pressupor que as atividades operacionais e de linha de frente não tem a menor chance de funcionar sem a presença de Recursos Humanos; - Oferecer treinamento para todos, de maneira indiscriminada; - Fazer com que os custos de pessoal não digam respeito à área de Recursos Humanos, e sim a cada setor, respectivamente.

Com o passar do tempo, há mudanças no mercado, trazendo demandas que pedem uma melhoria nas empresas. Mudanças essas que fizeram da Gestão de Pessoas um transformador na sociedade. Trazendo ao Colaborador as qualificações que a partir de então lhe passa a ser exigidas. Claro e Nickel (2002, p. 17) dizem que, "já faz algum tempo que a área de Recursos Humanos passou de um simples departamento de pessoal para um agente de transformação na organização, provocando mudanças e oferecendo sustentação na implantação da mesma".

Diante de tamanha mudança na sociedade, o autor Ribeiro (2005, p. 17), traz o novo papel do Recursos Humanos. São eles:

Propor, definir e garantir um conjunto de normas e procedimentos alinhados com os princípios empresariais e de acordo com a Legislação Trabalhista; - Criar e operar sistemas que permitam que as oportunidades de emprego e desenvolvimento de carreira estejam disponíveis a todos; - Dar suporte às demais unidades da empresa prestadora de serviços ou funcionar como facilitador nos processos de administração de pessoas; - Dar suporte as demais unidades da empresa no recrutamento e desenvolvimento de pessoas; - Criar, propor e administrar instrumentos que possibilitem uma remuneração competitiva a todos os funcionários; - Buscar sempre a diversidade, com o objetivo principal de aumentar o capital intelectual, de modo a garantir a capacidade de atualização e inovação da empresa; - Ver as pessoas e a organização como seres espirituais e ajudá-las a dar o próximo passo em seu processo de desenvolvimento; - Ter no treinamento a principal ferramenta para retenção do capital humano, e desenvolver novas competências para atual era empresarial; - Dignificar o trabalho e o ser 
humano. A Gestão de Pessoas é contingencial e situacional, pois dependem de vários aspectos com a estrutura organizacional adotada, a cultura que existe em cada organização, as características do contexto ambiental, o negócio da empresa, os processos internos e outras variáveis. (CHIAVENATO, 1999, p. 32).

Dentro dos objetivos da Gestão de Pessoas, não se pode esquecer alguns pontos essenciais para o seu desenvolvimento, como por exemplo, prestar um auxílio à organização para que esta consiga atingir suas metas e objetivos, bem como realizar sua missão; há também a questão de propor uma disputa à empresa; o treinamento e a motivação as pessoas da empresa são imprescindíveis; propor aos funcionários uma satisfação dentro da empresa; tem que haver uma qualidade de vida destes funcionários na empresa; e por último, mas não menos importante, sustentar o respeito, bem como a ética e um comportamento social responsável dentro da empresa. (CHIAVENATO, 1999).

De tal modo, a Gestão de Pessoas veio para que a empresa agregasse valor a si, fazendo com que este gere retorno aos acionistas e proporcione ganhos para todos àqueles que estão envolvidos. Segundo o autor Chiavenato, existem seis processos que são básicos para a Gestão de pessoas. São elas:

Processos de Agregar Pessoas: São os processos de incluir novas pessoas, de suprimento de novos funcionários. Nesse processo estão as atividades de recrutamento e seleção de pessoas. 2- Processos de Aplicar Pessoas: Processos utilizados para modelar as atividades que os funcionários irão realizar na organização, acompanhar e orientar seu desempenho. As atividades encontradas nesse processo são de desenhos de cargos e avaliação de desempenho. 3- Processos de Recompensar Pessoas: Processos utilizados para motivar e incentivar as pessoas e satisfazer suas necessidades individuais. Nesse processo podemos encontrar as atividades de remuneração e benefícios. 4Processos de Desenvolver Pessoas: Processos utilizados para capacitar, treinar e desenvolver pessoas. Aqui encontramos as atividades de treinamento, mudanças e comunicação. 5- Processos de Manter as Pessoas: São os processos de criação de condições ambientais e psicológicas satisfatórias para o trabalho dos funcionários. 6- Processos de Monitorar Pessoas: São os processos utilizados para acompanhar e controlar 0 trabalho dos funcionários e analisar os resultados. Inclui nesse processo o banco de dados e sistemas de informações gerenciais. (CHIAVENATO, 1999. p. 6-13). 
Conforme exposto, pode-se observar que, todos esses processos agem conjuntamente, onde ambos se influenciam reciprocamente, fazendo assim das pessoas, seres importantes e valorizados dentro das empresas.

Chiavenato (2011, p. 10) diz que, "as pessoas constituem parte integrante do capital intelectual dentro da organização, e que as organizações bem-sucedidas se deram conta disso e tratam as pessoas como parceiras do seu negócio e fornecedores de competências e não mais como simples empregados contratados".

Pelo fato de as pessoas passarem uma boa parte de suas vidas dentro de organizações, estas têm a responsabilidade pelo o destino da empresa. Onde, no momento em que a empresa atinge suas metas empresariais, da mesma forma os colaboradores atingem suas metas, isto é, tanto a empresa quanto os colaboradores estão conectados entre si, onde um depende do outro, para que haja um mútuo benefício recíproco. (CHIAVENATO, 2011).

\section{UM BREVE HISTÓRICO DO COMPORTAMENTO ORGANIZACIONAL}

O autor Robbins (2010, p. 5) diz que, "habilidades humanas são definidas pela capacidade de se trabalhar com outras pessoas, buscando compreendê-las e motiválas tanto individualmente quanto em grupos". Muitas destas pessoas são tecnicamente proficientes, mas, incompetentes nos relacionamentos interpessoais. Pessoas essas que não são boas ouvintes e são incapazes de entender as necessidades dos outros, e têm dificuldades em administrar conflitos.

Como explanado pelo autor, as habilidades humanas são misteres e cabíveis em todo lugar. Mas as Habilidades Humanas são mais conhecidas como Comportamento Organizacional. Para Robbins, (2010, p.7), Comportamento Organizacional é: "um campo de estudos que investiga o impacto que indivíduos, grupos e a estrutura organizacional têm sobre o comportamento das pessoas dentro das organizações, com o propósito de utilizar esse conhecimento para melhorar a eficácia organizacional". 
O Comportamento Organizacional pode ser considerado um Campo de Estudos. Onde o mesmo volta-se a prever, explicar, entender e modificar o comportamento do ser humano dentro das organizações. Abaixo deste conceito de Comportamento Organizacional, há três considerações que também são importantes.

O comportamento organizacional enfoca comportamentos observáveis, como falar em reuniões, usar equipamentos de produção ou redigir um relatório. Também lida com os estados internos, como pensar, perceber e decidir, que acompanham as ações visíveis. 2- O comportamento organizacional envolve a análise do comportamento das pessoas tanto como indivíduos quanto como membros de unidades sócias maiores. 3O comportamento organizacional também avalia o "comportamento" desses grupos e organizações por si. Nem os grupos nem as organizações se "comportam" do mesmo jeito que as pessoas. Entretanto, nas organizações ocorrem certos eventos que não podem ser explicados apenas como resultado de comportamentos individuais. Esses eventos devem ser examinados em termos de processos grupais ou organizacionais. (WAGNER, 2012, p.5).

Para que as organizações trabalhem mais eficazmente e para que haja sucesso dentro das mesmas, o comportamento organizacional aplica o conhecimento sobre as pessoas e os grupos. Como diz Robbins (2010), o comportamento organizacional vai se ocupar do estudo sobre o que o ser humano faz nas organizações e de como esse comportamento afetará o desempenho organizacional, e como este estudo está voltado para situações relacionadas ao vínculo entre pessoas e as organizações, ressalta-se o comportamento relativo a tarefas, trabalho, absenteísmo, rotatividade, produtividade, desempenho e administração.

Conforme o Comportamento Organizacional foi se desenvolvendo, o mesmo foi divido em três áreas distintas. São elas: Comportamento Micro Organizacional; Comportamento Meso Organizacional e Comportamento Macro Organizacional.

O Comportamento Micro Organizacional busca abranger o comportamento do ser humano ao trabalhar sozinho. E para este tipo de comportamento, Robbins (2012) diz que há três áreas da Psicologia que foram as vertentes do Comportamento Organizacional. São elas: Psicologia Experimental: forneceu as teorias sobre a aprendizagem, motivação, percepção e estresse; Psicologia Clínica: contribuiu com 
os modelos de personalidade e de desenvolvimento humano; Psicologia Industrial: ofereceu teorias sobre seleção de colaboradores, atitudes no local de trabalho e avaliação de desempenho.

O Comportamento Meso Organizacional busca compreender o comportamento do ser humano que trabalha em equipes e em grupo. Onde, segundo Wagner (2012), o comportamento meso organizacional desenvolveu-se a partir de pesquisas nos campos da comunicação, da psicologia social e da sociologia interacionista, que forneceram teorias sobre tópicos como socialização, liderança e dinâmica de grupo.

O Comportamento Macro Organizacional busca dar enfoque a comportamentos de empresas pequenas. Para Wagner (2012), tais comportamentos podem ter origem e ser situados em quatro disciplinas, são elas: A Sociologia, com suas teorias sobre estrutura, status social e relações institucionais. A Ciência Política, com suas teorias sobre poder, conflito, negociação e controle. A Antropologia, com suas teorias sobre simbolismo, influência cultural e análise comparativa. A Economia, com suas teorias sobre competição e eficiência.

É visto que, cada área do Comportamento Organizacional ajuda a resolver certos tipos de problemas como; no Comportamento Micro Organizacional busca ver como que as pessoas sentem o seu local de trabalho? Ou, o que motiva os funcionários a fazerem suas tarefas? Já no Comportamento Meso Organizacional, busca-se saber quais as formas de socialização incentivam os colegas de trabalho a cooperar? Ou, como um gerente poderá determinar qual líder potencial será o mais eficaz? E no Comportamento Macro Organizacional procura-se saber, como o poder é adquirido e retido? Ou, quais os mecanismos podem ser usados para coordenar atividades de trabalho? (ROBBINS, 2012, p. 45).

Dentro de tais explicações, ver-se que o Comportamento Organizacional é de suma importância dentro de qualquer organização, fazendo valer a sua aplicação da teoria na prática.

\section{O COMPORTAMENTO ORGANIZACIONAL}

Subentende-se que, o Comportamento Organizacional influencia no clima dentro das organizações pautando quais as impressões e visões que os colaboradores têm da 
empresa onde estão. Para isso, o Comportamento Organizacional conta com a ajuda de algumas matérias de suma importância e que contribuem para o mesmo. São elas: a Psicologia, Psicologia Social, Sociologia e Antropologia.

O autor Robbins (2010) explana um pouco sobre a importância dessas matérias. Robbins (2010, p. 33) diz que, "a Psicologia é a ciência que busca medir, explicar e por algumas vezes modificar o comportamento dos seres humanos e dos animais". Aqueles que contribuem nessa área do comportamento organizacional são os que estudam as teorias relativas ao processo de aprendizagem e de personalidade, os psicólogos clínicos e, principalmente os psicólogos organizacionais e industriais, onde recentemente a contribuição dos psicólogos se estendeu para estudos sobre aprendizagem, percepção, personalidade, emoções, treinamento, eficácia de liderança, necessidades e forças motivacionais, satisfação com o trabalho, comprometimento organizacional, processos de tomada de decisão, avaliações de desempenho, mensuração de atitudes, técnicas de seleção de pessoal, desenho de cargo e estresse ocupacional.

Em relação à Psicologia Social, o autor Robbins (2010, p. 36) expõe que esta área é um campo da psicologia em que há um misto desta ciência com a sociologia, exercendo assim a influência de um ser sobre outro. Áreas como redirecionamento de atitudes, um modelo de comunicação, o progresso da confiança e uma observação do comportamento do grupo, são áreas em que os psicólogos sociais contribuem, principalmente dentro de uma empresa.

Quanto á Sociologia, Robbins (2010) diz que os sociólogos contribuíram para o comportamento organizacional por meio de estudos sobre o comportamento dos grupos dentro das organizações, onde por sua vez, os sociólogos estudam a cultura organizacional, teoria e estrutura organizacional, tecnologia organizacional, comunicação, poder e conflito.

E por último, a Antropologia, que segundo Robbins (2010) é o estudo das sociedades para compreender os seres humanos e suas atividades, fazendo valer que o trabalho dos antropólogos sobre culturas e ambientes, tem nos ajudado a compreender melhor 
as diferenças de valores, atitudes e comportamentos fundamentais entre povos de diferentes países ou de pessoas em ariadas organizações.

Conforme exposto, pode-se entender que, tais matérias são de extrema importância para o fundamento do Comportamento Organizacional, contribuindo de sua melhor maneira para o bem-estar das organizações. O estudo do Comportamento Organizacional faz-se importante na medida em que este influencia grandemente dentro de todas as organizações, fazendo com que haja mudanças significativas e positivas nas mesmas.

Fazer uma análise sobre o comportamento organizacional, proporciona um entendimento de como proceder em relação às pessoas, os grupos e a organização, fazendo com que esses seres consigam melhorar o desenvolvimento da organização, bem como seus resultados e o bem-estar daqueles que trabalham na organização.

Conforme já explanado, pode-se entender que o Comportamento Organizacional estuda as ações que os indivíduos, os grupos e a estrutura da organização exercem sobre o comportamento dentro das empresas com o intuito de usar tais estudos para a melhoria dos processos gerenciais.

O autor Wagner (2012) diz que o comportamento organizacional é um campo de pesquisa que por sua vez ajuda a prever, explicar e entender certos comportamentos que ocorrem nas e entre as organizações. E que as três áreas do comportamento organizacional (comportamento micro, meso e macro organizacional) têm ações diferentes entre as disciplinas científicas que contribuíram para a fundação do campo.

De certo modo, cada comportamento enfoca um aspecto diferente do comportamento organizacional, sendo que, o comportamento micro organizacional tem base nos atributos e no desempenho dos indivíduos nas organizações. Já o comportamento meso organizacional enfoca as características dos grupos e o comportamento das pessoas em equipes. E o comportamento macro organizacional discute os comportamentos das organizações tais como entidades. 
De tal modo, verifica-se a importância do Comportamento Organizacional dentro das organizações, valorizando o seu colaborador, para que este por sua vez possa trazer benefícios para a empresa, e que ao mesmo tempo a empresa também se torna beneficiada por não haver certos conflitos entre os colaboradores.

\section{METODOLOGIA}

Para que se chegasse a tais objetivos que levaram a realização deste artigo, foi realizada a pesquisa bibliográfica.

Segundo o autor Cervo; Bervian (2002), este diz que a pesquisa bibliográfica propõe explicar determinada situação mediante referências teóricas que foram publicadas em documentos, por exemplo, e que esta procura saber e investigar quais as colaborações presentes sobre o tema que está sendo pesquisado, onde este método de pesquisa utilizada, normalmente é o primeiro passo a ser dado em qualquer pesquisa científica.

Pesquisa essa que teve embasamento teórico em alguns livros como: Introdução à Teoria Geral da administração; Novos desafios da Gestão de Pessoas; Administração de Recursos Humanos; Gestão de Pessoas; Comportamento Organizacional; etc., onde alguns dos autores foram Chiavenato, Robbins e John, alguns dos mais citados no decorrer do artigo.

Foram utilizados também, revistas, artigos e alguns sites que trazem informações acerca do tema abordado, sendo referenciada a Administração, a Gestão de Pessoas e o Comportamento Organizacional.

Para tanto, Oliveira (2002, p. 14) diz que, "a técnica bibliográfica busca encontrar as fontes primárias e secundárias e materiais científicos e tecnológicos que são necessários para a realização do trabalho científico ou técnico científico". 


\section{RESULTADOS}

No presente artigo foi relatado a importância da Gestão de Pessoas e seus processos dentro das organizações, fazendo com que esta desenvolva um papel socializador dentro das empresas, entre ambas, e entre os colaboradores, mostrando também que o próprio colaborador tem o seu valor, e que, se bem tratado pode trazer mais benefícios para a empresa.

O autor Chiavenato (2002, p. 20) diz que, "a Gestão de Pessoas se baseia em três aspectos fundamentais: 1 . As pessoas como seres humanos; 2 . As pessoas são como meros recursos (humanos) organizacionais; 3. As pessoas como parceiras da organização".

Foi observado no decorrer do trabalho, que o Comportamento Organizacional se faz mister tanto para as Organizações, quanto para os Colaboradores, onde ambos trabalham juntos para que haja uma comunhão de interesses.

Foi explanado também que, para que o Comportamento Organizacional obtivesse êxito atualmente, este contou com o estudo e a ajuda de algumas matérias, como a Psicologia, Psicologia Social, Sociologia e Antropologia, que da sua forma contribuíram significantemente para o crescimento deste comportamento, onde cada estudo feito nessas matérias agiu consequentemente no estudo sobre as ações do homem individualmente e em grupo, onde estes estudos influenciaram em novas descobertas sobre as atitudes do ser humano dentro das organizações.

Mediante tais situações, surge então o comportamento micro organizacional, comportamento meso organizacional e o comportamento macro organizacional. Onde cada um tem a sua relevância e particularidade, tais comportamentos trouxeram meios de trabalhar o indivíduo sozinho, e centrou-se no entendimento dos comportamentos das pessoas que trabalham em equipes e grupos e teve destaque no comportamento de empresas inteiras. (WAGNER, 2012)

\section{CONSIDERAÇÕES FINAIS}


Pretendeu-se neste trabalho proporcionar, de forma sintética, mas objetiva, uma análise sobre o Comportamento Organizacional. Para tanto, primeiramente foi explanado sobre a Administração, fazendo destaque sobre a organização e sobre a Gestão de Pessoas. Onde, para Chiavenato (2010) a Administração faz as coisas acontecerem, e a mesma envolve simultaneamente a arte, a técnica e a ciência.

Sobre a Gestão de Pessoas, Chiavenato (1999) comenta que esta é o conjunto de decisões integradas sobre as relações de emprego que influenciam a eficácia dos funcionários e das organizações. De tal modo, foi explanado no decorrer do trabalho sobre a importância do Comportamento Organizacional, onde o mesmo pode ser considerado um campo de estudos, que de certa forma, o mesmo volta-se a prever, explicar, entender e modificar o comportamento do ser humano dentro das organizações.

Para tanto, o presente estudo trouxe significativos conhecimentos sobre o Comportamento Organizacional, fazendo valer que é preciso valorizar o colaborador, para que este consequentemente possa contribuir de forma valorosa para a organização, onde ambos somente irão ganhar tendo valiosa atitude.

Este trabalho contribui para que a sociedade, e mais especificamente os (as) estudantes de recursos humanos, possam ter um melhor entendimento do que seja o Comportamento Organizacional e quais os seus benefícios para as organizações e para os colaboradores.

\section{REFERÊNCIAS}

Administração de recursos humanos. Fundamentos Básicos. 5. ed. São Paulo: Atlas, 2002.

Administração: teoria, processo e prática / Idalberto Chiavenato. 5ed. Barueri, SP: Manole, 2014.

CERVO, A. L.; BERVIAN, P. A. Metodologia científica. 5. ed. São Paulo: Prentice Hall, 2002. 
CHIAVENATO. I. Administração nos novos tempos. 2. ed. Rio de Janeiro: Campus, 1999.

. I. Empreendedorismo: dando asas ao espírito empreendedor: empreendedorismo e viabilidade de novas empresas: um guia eficiente para iniciar e tocar seu próprio negócio. 2.ed. ver. E atualizada. - São Paulo: Saraiva, 2012.

CLARO. MAPM; NICKEL, D. C. Gestão do Capital Humano. Editora: São Paulo, 2002.

DESSLER. G. Administração de recursos humanos. Pearson Brasil, 2003.

REIBERGER. Z. Comportamento organizacional. Cuiabá: EdUFMT, 2009.

GIL. A. C. Gestão de pessoas: enfoque nos papéis profissionais. São Paulo: Atlas, 2001.

OLIVEIRA, S. L. Metodologia científica aplicada ao direito. São Paulo: Pioneira Thomson Learning, 2002.

ROBBINS. S. O segredo na Gestão de Pessoas. Edições Centro Atlântico. 2010.

S. Biblioteca Gestão sem Segredos. Edições Centro Atlântico, 2012.

WAGNER. J. Comportamento organizacional: criando vantagem competitiva.

Tradução Silvio Floreal Antunha. - São Paulo: Saraiva, 2012.

Enviado: Julho, 2020.

Aprovado: Novembro, 2020. 